http://jmscr.igmpublication.org/home/ ISSN (e)-2347-176x ISSN (p) 2455-0450 crossref DOI: https://dx.doi.org/10.18535/jmscr/v8i2.61

\author{
(D) Journal Of Medical Science And Clinical Research \\ IGM Publication \\ An Official Publication of IGM Publication
}

\title{
Osler Weber Rendu Syndrome - An Interesting Case Report
}

\author{
Authors \\ Dr R.Rathipriyadharshini ${ }^{1}$, Dr M.S.Srinivasan ${ }^{2}$ \\ ${ }^{1}$ Junior Resident, ${ }^{2} \mathrm{Head}$ of the Department
}

Department of Dermatology, Venereology and Leprosy, Chettinad Hospital and Research Institute,

Kelambakkam

Corresponding Author

\section{Dr R. Rathipriyadharshini}

Junior Resident, Department of Dermatology, Venereology and Leprosy, Chettinad Hospital and Research Institute, Kelambakkam, India

\begin{abstract}
Osler weber rendu syndrome] is a rare autosomal dominant inherited disorder with late onset penetrance associated with extreme phenotypic variations. Here we present a case with typical clinical features diagnosed prior life-threatening visceral involvement.
\end{abstract}

Keywords: Autosomal dominant, phenotypic variations, visceral Involvement, Life-threatening.

\section{Introduction}

Osler weber rendu syndrome also known as Hereditary Hemorrhagic Telangiectasia [HHT] is a rare genetic disorder transmitted in autosomal dominant manner characterised by recurrent bouts of epistaxis, multiple mucocutaneous telangiectasias \& visceral arteriovenous malformations. ${ }^{[1]}$ It can present at any age ${ }^{[2]}$ with wide spectrum of manifestations being completely symptomatic at one end to multi-organ dysfunction at other end.

\section{Case Report}

52 years old male patient presented with multiple reddish spots over both hands and mouth for past 3 months.

$\square$ He also had history of spontaneous bleeding from lesions over tongue
History of recurrent epistaxis was present for past 10 years for which he has been on symptomatic treatment.

- No history of gum bleeding, abdominal pain, hematemesis or melena or hemoptysis

- No history of headache, black outs, seizures or visual disturbances

$\square$ No history of bluish discoloration of nose, ear / fingertips.

No History of any joint pain / swelling

口 Known hypertensive on medications for past 10 years.

$\square$ Recently diagnosed Type 2 Diabetes Mellitus started on oral hypoglycaemics.

- Family history revealed that his own brother and nephew are having similar complaints

Detailed cutaneous examination revealed multiple macular erythematous lesions over both palms [Fig 1] and multiple compressible erythematous non 


\section{JMSCR Vol||08||Issue||02||Page 343-345||February}

pulsatile papular lesions over dorsal and ventral surface of tongue and soft palate [Fig 2]. Lesions over the palms were completely blanchable on diascopy. General examination revealed pallor. There was no organomegaly/ lymphadenopathy. Based on clinical examination, Angina bullosa hemorrhagica, HHT, Lymph-hemangioma of tongue were considered.

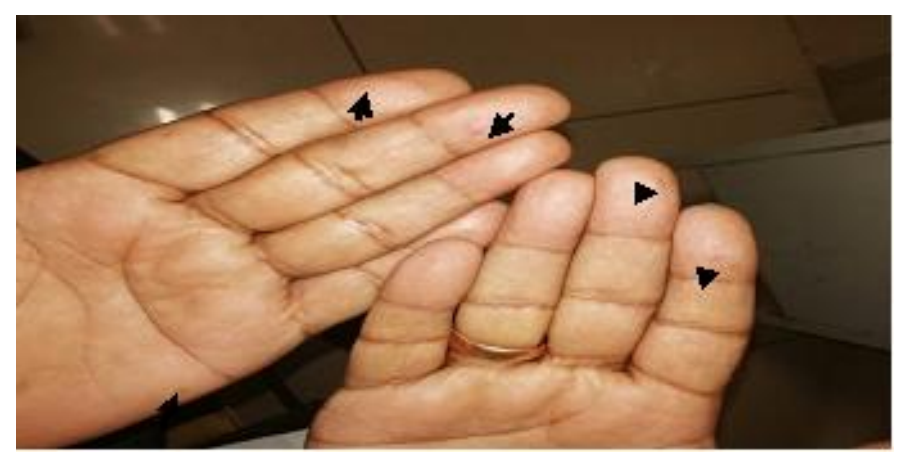

Fig.1 showing Telangiectasias over both palms

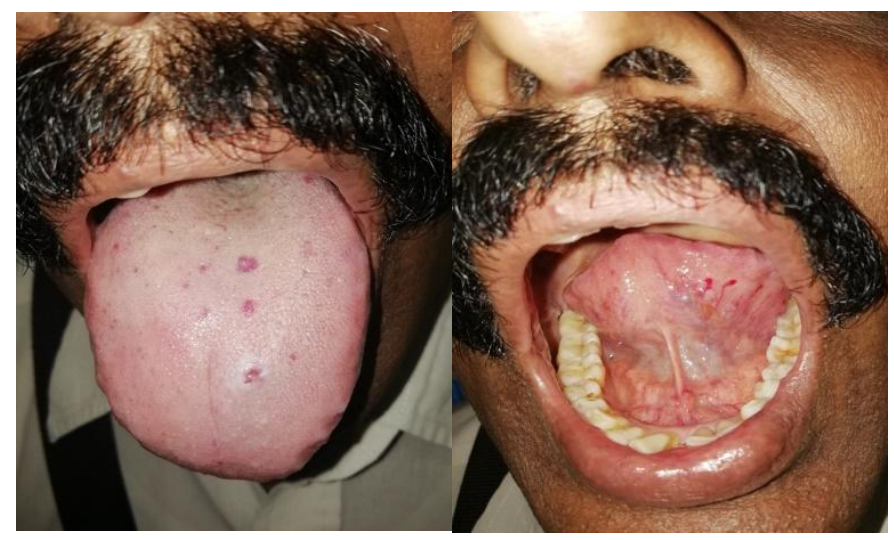

Fig.2 showing mucosa telangiectasias over dorsal and ventral tongue

Blood investigations revealed Hemoglobin9.5 g\%, Peripheral smear showed microcytic hypochromic anaemia. Bleeding time, Clotting time, Prothrombin Time and APTT were normal.

Coagulation profile was within normal limits. Absolute platelet count was 3.2 lakhs. Stool for occult blood was negative. Chest $\mathrm{X}$ ray, USG abdomen and CT Brain revealed no abnormalities. Histopathology revealed dilated capillaries. [Fig.3]

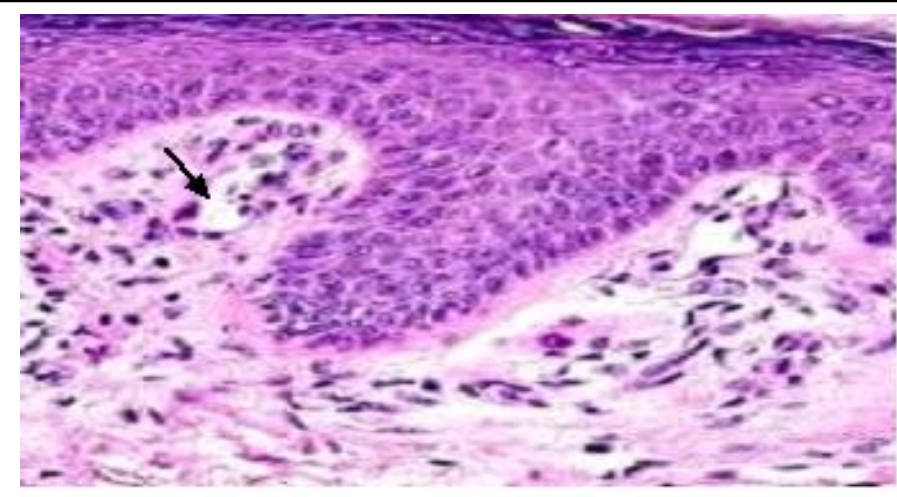

Fig.3. Histopathological examination showing thin walled dilated capillaries

Hence as the patient fulfilled 3 out of 4criterias in Curacao's diagnostic criteria, patient was diagnosed as a case of HHT.

\section{Discussion}

Osler-Weber-Rendu syndrome is a rare inherited vessel wall abnormality with an incidence of 1$2 / 10000$ causing systemic fibrovascular dysplasia. Genetic studies revealed 6 different gene involvement $^{[2]}$.

- Four identified (ENG, ACVRL1, SMAD4, GDF2)

- Two localized (HHT3 on chromosome 5q31.3- q32, ${ }^{[4]}$ and HHT4 on chromosome $7 \mathrm{p} 14)^{[3]}$

These genes were found to encode components of TGF-beta signalling pathway which play a role in angiogenesis \& vessel wall integrity. Primary manifestation is epistaxis in most cases which starts in childhood / around puberty. Mucocutaneous telangiectasias are nothing but AVM which appear after puberty and increase in size \& no as the patient ages. Three varieties of telangiectasias have been described. [Table 1]

Table 1 Types of Telangiectasias

\begin{tabular}{|l|}
\hline Discrete red punctum[Most common] \\
\hline Spider nevi/ nevus araneus \\
\hline Linear/ branched types \\
\hline
\end{tabular}

Gastrointestinal \& genitourinary tract hemorrhages manifest later in life leading to iron deficiency anaemia / life threatening complications like pulmonary, hepatic / cerebral hemorrhages. 
Diagnosis is based on Curacao's Criteria put forth by International Foundation on HHT. ${ }^{[6]}$ Three of the criteria should be fulfilled for definite diagnosis and diagnosis is possible if two are present. If less than two criteria are met then the diagnosis is unlikely.

Table 2 Curacao Diagnostic criteria ${ }^{[5]}$

\begin{tabular}{|c|}
\hline Epistaxis- spontaneous recurrent nose bleeds \\
\hline $\begin{array}{l}\text { Telangiectasias }- \text { multiple , at characteristic sites( lips, oral } \\
\text { cavity, fingers ,nose) }\end{array}$ \\
\hline $\begin{array}{r}\text { Visceral lesions } \\
\text { - } \\
\text { GI Telangiectasias } \\
\text { AVmalformations(pulmonary, hepatic, } \\
\text { cerebral/spinal) }\end{array}$ \\
\hline Family history $-1^{\text {st }}$ degree relative with HHT \\
\hline
\end{tabular}

Our case met three of the above mentioned criteria and is unique because the diagnosis was made before development of visceral involvement which may result in life threatening complications. Anemia seen in our patient might be the result of recurrent bleeding from his mucosal lesions. The patient was managed with iron supplementation and the mucocutaneous manifestations were managed with diathermy and the patient is on regular follow up for early detection of visceral manifestations.

Treatment in HHT is multidisciplinary.Primarily supportive management should be done with iron supplementation for milder cases as in this case, to Blood tranfusion in severe cases. Surgical ligation, embolectomy or radiosurgery may be needed in visceral AV malformations. Diathermy, sclerotherapy, infrared coagulation or laser ablation have been tried in localised mucocutaneous lesions. [6][8] Systemic therapy has been tried using Thalidomide $^{[7]}$ and anti-VEGF antibodies like Bevacizumab. ${ }^{[9]}$

\section{References}

1. Guttmacher AE, Marchuk DA, White Jr RI. Hereditary hemorrhagic telangiectasia. New England Journal of Medicine. 1995 Oct 5;333(14):918-24.

2. Shovlin CL, Hughes JM, Scott J, Seidman CE, Seidman JG. Characterization of endoglin and identification of novel mutations in hereditary hemorrhagic telangiectasia. The American Journal of Human Genetics. 1997 Jul 1;61(1):68-79.

3. Bayrak- Toydemir P, McDonald J, Akarsu N, Toydemir RM, Calderon F, Tuncali T, Tang W, Miller F, Mao R. A fourth locus for hereditary hemorrhagic telangiectasia maps to chromosome 7. American journal of medical genetics Part A. 2006 Oct 15;140(20):2155-62.

4. Cole SG, Begbie ME, Wallace GM, Shovlin CL. A new locus for hereditary haemorrhagic telangiectasia (HHT3) maps to chromosome 5. Journal of medical genetics. 2005 Jul 1;42(7):577-82.

5. Shovlin CL, Guttmacher AE, Buscarini E, Faughnan ME, Hyland RH, Westermann CJ, Kjeldsen AD, Plauchu H. Diagnostic criteria for hereditary hemorrhagic telangiectasia (Rendu- Osler- Weber syndrome). American journal of medical genetics. 2000 Mar 6;91(1):66-7.

6. Colver GB, Davies S, Bullock J. Infra red coagulation for bleeding mucosal telangiectasia. The Journal of Laryngology \& Otology. 1992 Nov;106(11):992-3.

7. Lebrin F, Srun S, Raymond K, Martin S, Van Den Brink S, Freitas C, Bréant C, Mathivet T, Larrivée B, Thomas JL, Arthur HM. Thalidomide stimulates vessel maturation and reduces epistaxis in individuals with hereditary hemorrhagic telangiectasia. Nature medicine. 2010 Apr;16(4):420.

8. Galletta A, Amato G. Hereditary hemorrhagic telangiectasia (Osler-RenduWeber disease) management of epistaxis and oral hemorrhage by Nd-Yag laser. Minerva stomatologica. 1998 Jun;47(6):283-6.

9. Bose P, Holter JL, Selby GB. Bevacizumab in hereditary hemorrhagic telangiectasia. New England Journal of Medicine. 2009 May 14;360(20):2143-4. 